Article

\title{
Pythagorean 2-Tuple Linguistic VIKOR Method for Evaluating Human Factors in Construction Project Management
}

\author{
Tingting He ${ }^{1}$, Guiwu Wei ${ }^{1}{ }^{(\mathbb{C}}$, Jianping Lu ${ }^{1}$, Cun Wei ${ }^{2}{ }^{\mathbb{C}}$ and Rui Lin ${ }^{3, *}$ \\ 1 School of Business, Sichuan Normal University, Chengdu 610101, China; m_hetingting@163.com (T.H.); \\ weiguiwu1973@sicnu.edu.cn (G.W.); lujp2002@163.com (J.L.) \\ 2 School of Statistics, Southwestern University of Finance and Economics, Chengdu 611130, China; \\ weicun1990@163.com \\ 3 School of Economics and Management, Chongqing University of Arts and Sciences, \\ Chongqing 402160, China \\ * Correspondence: linrui@cqwu.edu.cn
}

Received: 28 October 2019; Accepted: 18 November 2019; Published: 24 November 2019

\begin{abstract}
Since the reform and opening up, Chinese economic and social development has undergone great changes, and the people's living standards have improved markedly. For the national economy, the engineering construction is not only a carrier for specific economic tasks, but also a driving force for rapid and sustained economic development. With the continuous expansion of the scale of construction projects, safety management problems of construction projects are constantly exposed. How to effectively avoid accidents has become an important issue to be solved urgently in the construction industry. This paper mainly evaluates human factors in the process of construction project management, such as workers' proficiency, workers' safety awareness, technical workers' quality, and workers' emergency capacity, with the purpose of helping China's construction projects proceed smoothly. In this research, we provide a multiple attribute group decision-making (MAGDM) technique based on Pythagorean 2-tuple linguistic numbers (P2TLNs) and the VIseKriterijumska Optimizacija I KOmpromisno Resenje (VIKOR) method for evaluating the human factors of construction projects. P2TLNs are used to represent the performance assessments of decision makers. Relying on a P2TLWA operator, P2TLWG operator, and the essential VIKOR method, a general framework is established. An application is presented to test the validity of the new method, and a comparative analysis with two algorithms and the P2TL-TODIM method is illustrated with detail.
\end{abstract}

Keywords: multiple attribute group decision making (MAGDM); Pythagorean 2-tuple linguistic numbers (P2TLNs); P2TLWA operator; P2TLWG operator; VIKOR method

\section{Introduction}

In the related projects of engineering construction, the management problem mainly involves the safety management problem, and is closely related to human, material, and environmental factors. Safety management problems involved in project construction management should be eliminated or avoided in time to ensure the timely and smooth completion of construction and protect the safety of construction personnel and property. However, in project management, the human factor plays a very important role, as it can effectively guide the construction project construction management results. Ning and Wang [1] promoted the TOPSIS method into an intuitionistic fuzzy environment to evaluate and select the optimal site selection scheme according to the specific attributes of the construction project, so as to effectively improve the construction operation and improve the safety of the working 
environment. Lu [2] studied how to utilize the 2-tuple linguistic model to deal with assessment information in the information management process of construction projects, and then followed the steps of TOPSIS model for evaluation. Gu et al. [3] introduced the IVIFECA (interval-valued intuitionistic fuzzy Einstein correlated averaging) operator, which was applied to choose construction projects. Wu et al. [4] expanded the HM (Hamy Mean) operator to 2TLNNs and then introduced some operators. Finally, they utilized these operators to assess the risk of construction projects.

The fuzzy set theory [5] was first introduced to describe the uncertainty and fuzziness of things. In order to reflect the objective world as faithfully as possible, many people offered some extended forms of the fuzzy set, such as IVHFS (interval-valued hesitant fuzzy set), T2FS (Type-2 fuzzy sets), IFS (intuitionistic fuzzy set) [6-11], etc. The IFS theory was proposed by Atanassov [6] in 1986 as an important extension of the classical fuzzy set theory [5]. The research on its theory and application has achieved extensive research results in the field of fuzzy set theory and produced far-reaching influence. In an intuitionistic fuzzy set, the membership degree was defined as the degree of affirmation about the same concept, and non-membership degree was defined as the degree of negation. However, when using intuitionistic fuzzy to make decisions, the following situation may occur: the membership degree plus non-membership degree of the scheme satisfying attributes given by the decision makers is greater than 1. Based on this, in 2013, the American scholar Yager [12] proposed the Pythagorean fuzzy set, which satisfies conditions where the membership degree plus non-membership degree is greater than 1 , but the sum of squares does not exceed 1 . Therefore, the decision maker does not need to modify the values of membership and non-membership, and thus the model can be a more accurate and detailed description of the reality [13-16].

After the Pythagorean fuzzy set was proposed, a large number of researchers combined the Pythagorean fuzzy set [12] with various methods and applied these proposed methods to MADM. Zhang and $\mathrm{Xu}$ [17] first put forward the mathematical expression of a Pythagorean fuzzy set, and then they tied the Pythagorean fuzzy set (PFS) and TOPSIS method together. Finally, they gave a practical example to illustrate the developed method and made a comparative analysis of different methods. Zhang [18] presented a Pythagorean fuzzy QUALIFLEX method with the closeness index to address the layered multi-criteria decision-making issue under a Pythagorean fuzzy environment on the basis of PFNs (Pythagorean fuzzy numbers) and IVPFNs (interval-valued Pythagorean fuzzy numbers). Ren et al. [19] provided a case of choosing the governor of the Asian Infrastructure Investment Bank by using the PF-TODIM (Pythagorean fuzzy TODIM) method to observe the feasibility of the model. Bolturk [20] expanded the CODAS (COmbinative Distance-based Assessment) model to Pythagorean fuzzy environment to propose a novel method that is PF-CODAS (Pythagorean fuzzy CODAS). They addressed a MADM problem of supplier selection utilizing the new method to show its validity and effectiveness. In the end, they concluded that the presented model has better results than the general fuzzy conclusion, because it takes into account the decision makers of dithering and expands the scope of membership and non-membership degree. Chen [21] defined a new VIseKriterijumska Optimizacija I KOmpromisno Resenje (VIKOR)-based method for MADM analysis containing Pythagorean fuzzy information. A Pythagorean fuzzy set has certain advantages over un-normalized fuzzy sets such as IFS (intuitionistic fuzzy set) in dealing with fuzziness and complex uncertainty. Based on this, a Pythagorean fuzzy VIKOR method based on a distance index is proposed, which is quite different from the existing VIKOR method. It is unique because that the model considers the uncertain information expressed by the PFNs and introduced some new concepts of measuring distance. Through the practical application and comparative analysis of a certain standard satisfaction problem, the validity and superiority of the used method in practice are verified. Huang and Wei [22] briefly introduced the definition of Pythagorean 2-tuple linguistic numbers (P2TLNs), which calculate the distance between two P2TLNs and the classic TODIM (an acronym in Portuguese for Interactive Multi-criteria Decision Making). On this basis, a new extended TODIM is put forward to deal with the MADM problem. The important feature of this method is to fully take the bounded rationality of the each decision maker into account, which is a practical behavior in the decision-making 
process. Finally, they also gave an example. Ilbahar et al. [23] proposed three methods, respectively: Fine Kinney, Pythagorean fuzzy analytic hierarchy process. Meanwhile, these methods are used to assess the excavation risk of a construction site. Based on the procedure of the classic TOPSIS method, Khan et al. [24] presented an extension of TOPSIS under the interval value Pythagorean fuzzy context, using the IVPFCIG (interval-valued Pythagorean fuzzy Choquet integral geometric) operator and distance formula based on the Choquet integral to aggregate all the fuzzy decision matrixes. Finally, it is proved by an example that the technique is practical and effective. Perez-Dominguez et al. [25] combined ratio analysis-based multiple objective optimization with a Pythagorean theorem fuzzy set to select an appropriate alternative. In the end, two decision problems illustrated that the method is valid and practical. A novel LINMAP (linear programming technique for multidimensional analysis of preference) method was expanded by Xue et al. [26] to the fuzzy environment of Pythagorean. Then, they defined PFE (Pythagorean fuzzy evalues) and IVPFE (interval-valued Pythagorean fuzzy evalues) based on similarity and hesitations. Based on the above, the PF-LINMAP method is constructed. According to a numerical example, this method can solve the decision problem related to railway project investment.

The VIseKriterijumska Optimizacija I KOmpromisno Resenje (Hereinafter referred to as VIKOR) model explored by Opricovic [27] initially is a practical tool to deal with the MADM problems and has a wide range of industrial, commercial economy, and science of management applications. Compared with previous methods, such as ELECTRE [28], PROMETHEE [29], GRA [30], TOPSIS [31], and TODIM [32-34], the advantage of the VIKOR model is that it takes into account the contradictory criteria such as the objectivity of decision makers and the complexity of the decision environment, so as to obtain more useful and scientific evaluation information.

Devi [35] explored a new expansion of VIKOR into an intuitionistic fuzzy context to solve the problem of a robot selection material handling task. Du and Liu [36] applied the VIKOR method in the fuzzy context of an intuitionistic trapezoidal to rank the pros and cons of each scheme and select the best one. Park et al. [37] proposed a new method to promote the VIKOR method to the interval value intuitionistic fuzzy environment to choose the right outsourcing partner for multinational organizations. Chatterjee et al. [38] gave an expanding VIKOR model based on IFS, which uses five criteria and four decision makers to evaluate five potential outsourcing partners. Finally, we choose the best outsourcer. Liao and $\mathrm{Xu}$ [39] contributed a new way of thinking that integrated the classical VIKOR method with hesitant fuzzy circumstances. An example is given to prove its validity. In order to solve the MADM problem of material selection in engineering design, an interval binary semantic VIKOR method is established to avoid information distortion and loss by Liu et al. [40]. Motivated by the traditional VIKOR method, Wei and Zhang [41] firstly defined the multiple criteria hesitant fuzzy decision making with shapley value-based VIKOR method. Using SLp, mu-metric, they developed an extended VIKOR method to handle related multi-criterion decision problems. Bausys and Zavadskas [42] solved a problem of selecting the location for a logistic terminal in a way where they tied the VIKOR method with interval-valued neutrosophic sets, namely VIKOR-IVNS. Dammak et al. [43] compared three methods based on intuitionistic fuzzy set respectively to TOPSIS, AHP (Analytical Hierarchy Process), and VIKOR, and analyzed the differences in the use of the three methods. Liao and $\mathrm{Xu}$ [44] constructed the cosine-distance-based HFL-TOPSIS model and the cosine-distance-based HFL-VIKOR model. Afterwards, they offered a case in point. You et al. [45] proposed the interval 2-tuple language VIKOR method for choosing the perfect supplier among three suppliers. It's worth noting that the method mentioned in this paper is more appropriate to treat with the problem of supplier selection in the context of fuzzy with uncertain and incomplete information. Buyukozkan et al. [46] integrated IF-AHP and IF-VIKOR to form an overall framework, and then used appropriate evaluation criteria to rank the web services of medical institutions according to the steps of the framework to measure the performance of 10 medical institutions in Turkey. Zhang et al. [47] proposed the hesitating fuzzy language VIKOR (HFL-VIKOR) method, and then took a West China hospital as an example to apply this method in the process of inpatient admission evaluation, so as to solve the problem of inpatient 
admission, which can be used for classified diagnosis and treatment. Hu et al. [48] adopted INSs (interval neutrosophic sets) to cope with evaluation information, and made use of a project-based difference measure VIKOR to solve the issue of online selection of doctors in mobile medical services. Wang et al. [49] explored a VIKOR method into a picture fuzzy context with normalized projection for the risk assessment of engineering construction projects.

Although previous studies deal with the selection of construction projects, they do not mention the evaluation of human factors in the process of construction project management. So, it is very essential to take appropriate measures to evaluate human factors by using relevant assessment criteria. In this paper, we extend the VIKOR method with Pythagorean 2-tuple linguistic numbers for the evaluation of human factors. It is our goal in this article to combine the original VIKOR method with P2TLNs to address MADM problems. The innovativeness of the paper can be summarized as follows: (1) the VIKOR method is extended by P2TLSs; (2) the Pythagorean 2-tuple linguistic VIKOR (P2TL-VIKOR) method is proposed to solve the Pythagorean 2-tuple linguistic multiple attribute group decision-making (MAGDM) problems; (3) a case study for evaluating human factors in construction project management is supplied to show the developed approach; and (4) some comparative studies are provided with the existing methods to give effect to the rationality of P2TL-VIKOR.

The remainder of this article is mainly as follows. Section 2 contains some basic definitions of P2TLNs; Section 3 contains the extending VIKOR method with P2TLNs; Section 4 provides a case study of evaluating human factors in the process of construction project management and contrastive analysis; and Section 5 presents the conclusions.

\section{Preliminaries}

\subsection{Pythagorean 2-Tuple Linguistic Sets}

Wei et al. [50] proposed the Pythagorean 2-tuple linguistic sets (P2TLSs) based on the PFSs [51] and 2-tuple linguistic information [52].

Definition 1 ([50]). A P2TLS A in X is given

$$
A=\left\{\left(s_{\varphi(x)}, \rho\right),\left(u_{A}(x), v_{A}(x)\right), x \in X\right\},
$$

where $s_{\varphi(x)} \in S, \rho \in[-0.5,0.5), u_{A}(x) \in[0,1]$, and $v_{A}(x) \in[0,1], u_{A}(x)$, and $v_{A}(x)$ satisfy the following condition: $0 \leq\left(u_{A}(x)\right)^{2}+\left(v_{A}(x)\right)^{2} \leq 1, \forall x \in X$. The numbers $u_{A}(x), v_{A}(x)$ represent the degree of membership and degree of non-membership of the element $x$ to linguistic variable $\left(s_{\varphi(x)}, \rho\right)$.

$$
A=\left\langle\left(s_{\varphi}, \rho\right),\left(u_{A}, v_{A}\right)\right\rangle \text { can be called a Pythagorean 2-tuple linguistic number (P2TLN). }
$$

Definition 2 ([50]). Suppose that $a=\left\langle\left(s_{\varphi}, \rho\right),\left(u_{a}, v_{a}\right)\right\rangle$ is a P2TLN; then, the score function of P2TLN can be depicted as follows:

$$
\begin{aligned}
& S(a)=\Delta\left(\Delta^{-1}\left(s_{\varphi(a)}, \rho\right) \frac{1+\left(u_{a}\right)^{2}-\left(v_{a}\right)^{2}}{2}\right), \\
& \Delta^{-1}(S(a)) \in[0, L] .
\end{aligned}
$$

Definition 3 ([50]). Suppose that $a=\left\langle\left(s_{\varphi}, \rho\right),\left(u_{a}, v_{a}\right)\right\rangle$ is a P2TLN; then, the accuracy function of P2TLN can be depicted as follows:

$$
\begin{aligned}
& H(a)=\Delta\left(\Delta^{-1}\left(s_{\varphi(a)}, \rho\right) \frac{\left(u_{a}\right)^{2}+\left(v_{a}\right)^{2}}{2}\right), \\
& \Delta^{-1}(H(a)) \in[0, L] .
\end{aligned}
$$


Definition 4 ([50]). Suppose that $a_{1}=\left\langle\left(s_{\varphi_{1}}, \rho_{1}\right),\left(u_{a_{1}}, v_{a_{1}}\right)\right\rangle$ and $a_{2}=\left\langle\left(s_{\varphi_{2}}, \rho_{2}\right),\left(u_{a_{2}}, v_{a_{2}}\right)\right\rangle$ are two P2TLNs. Respectively, the scores of $a_{1}$ and $a_{2}$ are $S\left(a_{1}\right)=\Delta\left(\Delta^{-1}\left(s_{\varphi\left(a_{1}\right)}, \rho_{1}\right) \cdot \frac{1+\left(u_{a_{1}}\right)^{2}-\left(v_{a_{1}}\right)^{2}}{2}\right)$ and $S\left(a_{2}\right)=\Delta\left(\Delta^{-1}\left(s_{\varphi\left(a_{2}\right)}, \rho_{2}\right) \cdot \frac{1+\left(u_{a_{2}}\right)^{2}-\left(v_{a_{2}}\right)^{2}}{2}\right)$, and let $H\left(a_{1}\right)=\Delta\left(\Delta^{-1}\left(s_{\varphi\left(a_{1}\right)}, \rho_{1}\right) \cdot \frac{\left(u_{a_{1}}\right)^{2}+\left(v_{a_{1}}\right)^{2}}{2}\right)$ and $H\left(a_{2}\right)=\Delta\left(\Delta^{-1}\left(s_{\varphi\left(a_{2}\right)}, \rho_{2}\right) \cdot \frac{\left(u_{a_{2}}\right)^{2}+\left(v_{a_{2}}\right)^{2}}{2}\right)$ be the accuracy degrees of $a_{1}$ and $a_{2}$; then, some operational laws of P2TLNs can be defined as follows:
(1) if $S\left(a_{1}\right)<S\left(a_{2}\right), a_{1}<a_{2}$;
(2) if $S\left(a_{1}\right)>S\left(a_{2}\right), a_{1}>a_{2}$;
(3) if $S\left(a_{1}\right)=S\left(a_{2}\right), H\left(a_{1}\right)<H\left(a_{2}\right)$, then $a_{1}<a_{2}$;
(4) if $S\left(a_{1}\right)=S\left(a_{2}\right), H\left(a_{1}\right)>H\left(a_{2}\right)$, then $a_{1}>a_{2}$;
(5) if $S\left(a_{1}\right)=S\left(a_{2}\right), H\left(a_{1}\right)=H\left(a_{2}\right)$, then $a_{1}=a_{2}$.

Definition 5 ([50]). Suppose that $a_{1}=\left\langle\left(s_{\varphi_{1}}, \rho_{1}\right),\left(u_{a_{1}}, v_{a_{1}}\right)\right\rangle$ and $a_{2}=\left\langle\left(s_{\varphi_{2}}, \rho_{2}\right),\left(u_{a_{2}}, v_{a_{2}}\right)\right\rangle$ are two P2TLNs, the normalized Hamming distance $\left(H_{d}\right)$ between $a_{1}$ and $a_{2}$ can be depicted below:

$$
H_{d}\left(a_{1}, a_{2}\right)=\frac{1}{2 L}\left[\begin{array}{c}
\left(1+\left(u_{a_{1}}\right)^{2}-\left(v_{a_{1}}\right)^{2}\right) \cdot \Delta^{-1}\left(s_{\varphi_{1}}, \rho_{1}\right)- \\
\left(1+\left(u_{a_{2}}\right)^{2}-\left(v_{a_{2}}\right)^{2}\right) \cdot \Delta^{-1}\left(s_{\varphi_{2}}, \rho_{2}\right)
\end{array} \|\right],
$$

where $L$ represents the length of the language scale. It is a numerical value.

Definition 6 ([50]). Suppose that $a_{1}=\left\langle\left(s_{\varphi_{1}}, \rho_{1}\right),\left(u_{a_{1}}, v_{a_{1}}\right)\right\rangle$ and $a_{2}=\left\langle\left(s_{\varphi_{2}}, \rho_{2}\right),\left(u_{a_{2}}, v_{a_{2}}\right)\right\rangle$ are two P2TLNs, then

$$
\begin{aligned}
& a_{1} \oplus a_{2}=\left\langle\Delta\left(\Delta^{-1}\left(s_{\varphi_{1}}, \rho_{1}\right)+\Delta^{-1}\left(s_{\varphi_{2}}, \rho_{2}\right)\right),\left(\sqrt{\left(u_{a_{1}}\right)^{2}+\left(u_{a_{2}}\right)^{2}-\left(u_{a_{1}}\right)^{2}\left(u_{a_{2}}\right)^{2}}, v_{a_{1}} v_{a_{2}}\right)\right\rangle ; \\
& a_{1} \otimes a_{2}=\left\langle\Delta\left(\Delta^{-1}\left(s_{\varphi_{1}}, \rho_{1}\right) \cdot \Delta^{-1}\left(s_{\varphi_{2}}, \rho_{2}\right)\right),\left(u_{a_{1}} u_{a_{2}}, \sqrt{\left(v_{a_{1}}\right)^{2}+\left(v_{a_{2}}\right)^{2}-\left(v_{a_{1}}\right)^{2}\left(v_{a_{2}}\right)^{2}}\right)\right\rangle ; \\
& \lambda a_{1}=\left\langle\Delta\left(\lambda \Delta^{-1}\left(s_{\varphi_{1}}, \rho_{1}\right)\right),\left(\sqrt{1-\left(1-\left(u_{a_{1}}\right)^{2}\right)^{\lambda}},\left(v_{a_{1}}\right)^{\lambda}\right)\right) ; \\
& \left(a_{1}\right)^{\lambda}=\left\langle\Delta\left(\left(\Delta^{-1}\left(s_{\varphi_{1}}, \rho_{1}\right)\right)^{\lambda}\right),\left(\left(u_{a_{1}}\right)^{\lambda}, \sqrt{\left.\left.1-\left(1-\left(v_{a_{1}}\right)^{2}\right)^{\lambda}\right)\right\rangle .}\right.\right.
\end{aligned}
$$

Theorem 1 ([50]). For any two P2TLNs $a_{1}=\left\langle\left(s_{\varphi_{1}}, \rho_{1}\right),\left(u_{a_{1}}, v_{a_{1}}\right)\right\rangle$ and $a_{2}=\left\langle\left(s_{\varphi_{2}}, \rho_{2}\right),\left(u_{a_{2}}, v_{a_{2}}\right)\right\rangle$; according to Definition 6, naturally, we can get the following properties of the operation laws:

$$
\begin{aligned}
& \text { (1) } a_{1} \oplus a_{2}=a_{2} \oplus a_{1} \\
& \text { (2) } a_{1} \otimes a_{2}=a_{2} \otimes a_{1} \\
& \text { (3) } k\left(a_{1} \oplus a_{2}\right)=k a_{1} \oplus k a_{2}, 0 \leq k \leq 1 \\
& \text { (4) } k_{1} a_{1} \oplus k_{2} a_{1}=\left(k_{1} \oplus k_{2}\right) a_{1}, 0 \leq k_{1}, k_{2}, k_{1}+k_{2} \leq 1 \\
& \text { (5) } a_{1} k_{1} \otimes a_{1} k_{2}=\left(a_{1}\right)^{k_{1}+k_{2}}, 0 \leq k_{1}, k_{2}, k_{1}+k_{2} \leq 1 \\
& \text { (6) } a_{1} k_{1} \otimes a_{2} k_{1}=\left(a_{1} \otimes a_{2}\right)^{k_{1}}, k_{1} \geq 0 \\
& \text { (7) }\left(\left(a_{1}\right)^{k_{1}}\right)^{k_{2}}=\left(a_{1}\right)^{k_{1} k_{2}} .
\end{aligned}
$$




\subsection{Pythagorean 2-Tuple Linguistic Arithmetic Aggregation Operators}

In this section, some arithmetic aggregation operators with Pythagorean 2-tuple linguistic information will be introduced, such as the P2TLWA operator and P2TLWG operator.

Definition 7 ([50]). Assume that $a_{j}=\left\langle\left(s_{\varphi_{j}}, \rho_{j}\right),\left(u_{a_{j}}, v_{a_{j}}\right)\right\rangle(j=1,2, \ldots, n)$ is a collection of P2TLNs. The P2TLWA operator can be depicted as follows:

$$
\begin{aligned}
& \operatorname{P} \operatorname{TLWA}_{\omega}\left(a_{1}, a_{2}, \ldots, a_{n}\right)=\bigoplus_{j=1}^{n}\left(\omega_{j} a_{j}\right) \\
& =\left\langle\Delta\left(\sum_{j=1}^{n} \omega_{j} \Delta^{-1}\left(s_{\varphi_{j}}, \rho_{j}\right)\right),\left(\sqrt{1-\prod_{j=1}^{n}\left(1-\left(u_{a_{j}}\right)^{2}\right)^{\omega_{j}}}, \prod_{j=1}^{n}\left(v_{a_{j}}\right)^{\omega_{j}}\right)\right\rangle,
\end{aligned}
$$

where $\omega=\left(\omega_{1}, \omega_{2}, \ldots, \omega_{n}\right)^{T}$ is the weight vector of $a_{j}(j=1,2, \ldots, n)$ and $\omega_{j}>0, \sum_{j=1}^{n} \omega_{j}=1$.

Definition 8 ([50]). Assume that $a=\left\langle\left(s_{\varphi_{j}}, \rho_{j}\right),\left(u_{a_{j}}, v_{a_{j}}\right)\right\rangle(j=1,2, \ldots, n)$ is a collection of P2TLNs. The P2TLWG operator can be depicted as follows:

$$
\begin{aligned}
& \operatorname{P}^{2} \operatorname{TLWG}_{\omega}\left(a_{1}, a_{2}, \ldots, a_{n}\right)=\stackrel{\otimes}{j=1}_{j}^{n}\left(\omega_{j} a_{j}\right) \\
& =\left\langle\Delta\left(\prod_{j=1}^{n} \Delta^{-1}\left(s_{\varphi_{j}}, \rho_{j}\right)^{\omega_{j}}\right),\left(\prod_{j=1}^{n}\left(u_{a_{j}}\right)^{\omega_{j}} \sqrt{1-\prod_{j=1}^{n}\left(1-\left(v_{a_{j}}\right)^{2}\right)^{\omega_{j}}}\right)\right\rangle,
\end{aligned}
$$

where $\omega=\left(\omega_{1}, \omega_{2}, \ldots, \omega_{n}\right)^{T}$ is the weight vector of $a_{j}(j=1,2, \ldots, n)$ and $\omega_{j}>0, \sum_{j=1}^{n} \omega_{j}=1$.

\section{VIKOR Method for P2TL MADM Problems}

Suppose that $\Phi_{i}=\left\{\Phi_{1}, \Phi_{2}, \ldots \Phi_{m}\right\}$ and $\tau_{j}=\left\{\tau_{1}, \tau_{2}, \ldots \tau_{n}\right\}$ are respectively $m$ alternatives and $n$ criteria. Let $\omega=\left\{\omega_{1}, \omega_{2}, \ldots \omega_{n}\right\}$ be the criteria's weighting vector, which satisfies $\omega_{j} \in[0,1]$ and $\sum_{j=1}^{n} \omega_{j}=1$. Let $E=\left\{E_{1}, E_{2}, \ldots E_{k}\right\}$ be the group of DMs, $w=\left\{w_{1}, w_{2}, \ldots w_{k}\right\}$ be the weight of DMs, with $w_{t} \in[0,1]$ and $\sum_{t=1}^{k} w_{t}=1$. Construct a decision matrix $R^{(t)}=\left(r_{i j}^{(t)}\right)_{m \times n}$, where $R^{(t)}=\left(r_{i j}^{(t)}\right)_{m \times n}=$ $\left\langle\left(s_{\varphi_{i j}}^{(t)}, \rho_{i j}^{(t)}\right),\left(u_{r_{i j}}^{(t)}, v_{r_{i j}}^{(t)}\right)\right\rangle_{m \times n}$ means the performance of the alternative $\Phi_{i}\{i=1,2 \cdots, m\}$ with respect to criteria $\tau_{j}\{j=1,2 \cdots, n\}$ by expert $E^{(t)}\{t=1,2, \ldots k\}$ using a P2TLN, $0 \leq u_{r_{i j}}^{(t)} \leq 1,0 \leq v_{r_{i j}}^{(t)} \leq 1$ and $0 \leq\left(u_{r_{i j}}^{(t)}\right)^{2}+\left(v_{r_{i j}}^{(t)}\right)^{2} \leq 1, i=1,2 \cdots, m, j=1,2 \cdots, n, t=1,2 \cdots, k$.

In view of both the P2TLN's theories and procedures from the VIKOR method, we put forward a P2TL-VIKOR method to deal with the problem of MADM effectively. The new model is shown below.

Step 1. Set up a decision-making group composed of several experts, choose the best attributes to measure alternatives, and finally get a series of P2TL fuzzy decision matrices $R^{(t)}=\left(r_{i j}^{(t)}\right)_{m \times n}$ from each decision maker.

$$
R^{(t)}=\left[r_{i j}^{(t)}\right]_{m \times n}=\left[\begin{array}{cccc}
r_{11}^{(t)} & r_{12}^{(t)} & \ldots & r_{1 n}^{(t)} \\
r_{21}^{(t)} & r_{22}^{(t)} & \ldots & r_{2 n}^{(t)} \\
\vdots & \vdots & \vdots & \vdots \\
r_{m 1}^{(t)} & r_{m 2}^{(t)} & \ldots & r_{m n}^{(t)}
\end{array}\right]
$$

where $r_{i j}^{(t)}$ denotes the fuzzy performance value of the $i$ th alternative $(i=1,2, \ldots, m)$ with respect to the $j$ th criterion $(j=1,2, \ldots, n)$ and $t$ th decision-maker $(t=1,2, \ldots, k)$. 
Step 2. Utilize the P2TLWA operator or P2TLWG operator to the fuse assessment information; then, the group P2TL fuzzy decision matrix $R=\left(r_{i j}\right)_{m \times n}$ can be obtained by the calculation.

$$
\begin{gathered}
R=\left[r_{i j}\right]_{m \times n}=\left[\begin{array}{cccc}
r_{11} & r_{12} & \ldots & r_{1 n} \\
r_{21} & r_{22} & \ldots & r_{2 n} \\
\vdots & \vdots & \vdots & \vdots \\
r_{m 1} & r_{m 2} & \ldots & r_{m n}
\end{array}\right], \\
r_{i j}=\underset{t=1}{\oplus} r_{i j}^{(k)}=\operatorname{P} 2 \operatorname{TLWA}\left(r_{i j}^{(1)}, r_{i j}^{(2)}, \ldots, r_{i j}^{(k)}\right) \\
=\left\langle\Delta\left(\sum_{t=1}^{k} w_{t} \Delta^{-1}\left(s_{\varphi_{i j}}^{(t)} \rho_{i j}^{(t)}\right)\right),\left(\sqrt{1-\prod_{t=1}^{k}\left(1-\left(u_{r_{i j}}^{(t)}\right)^{2}\right)^{w_{t}}}, \prod_{t=1}^{k}\left(v_{r_{i j}}^{(t)}\right)^{w_{t}}\right)\right\rangle .
\end{gathered}
$$

Or

$$
\begin{aligned}
& r_{i j}=\stackrel{\otimes}{t=1}_{i j}^{(k)} r_{i j}^{(k)}=\operatorname{P2TLWG}\left(r_{i j}^{(1)}, r_{i j}^{(2)}, \ldots, r_{i j}^{(k)}\right) \\
& =\left\langle\Delta\left(\prod_{t=1}^{k} \Delta^{-1}\left(s_{\varphi_{i j}}^{(t)} \rho_{i j}^{(t)}\right)^{w_{t}}\right),\left(\prod_{t=1}^{k}\left(u_{r_{i j}}^{(t)}\right)^{w_{t}}, \sqrt{1-\prod_{t=1}^{k}\left(1-\left(v_{r_{i j}}^{(t)}\right)^{2}\right)^{w_{t}}}\right)\right\rangle
\end{aligned}
$$

Here, $r_{i j}$ means the average fuzzy performance value of the $i$ th alternative relative to the $j$ th criterion.

Step 3. Determine the positive ideal solutions $R_{j}^{+}$and negative ideal solutions $R_{j}^{-}$.

$$
\begin{aligned}
& R_{j}^{+}=\left\{\left(\Delta^{-1}\left(s_{\varphi_{j}}, \rho_{j}\right)\right)^{+},\left(u_{a_{j}}^{+}, v_{a_{j}}^{+}\right)\right\}, \\
& R_{j}^{-}=\left\{\left(\Delta^{-1}\left(s_{\varphi_{j}}, \rho_{j}\right)\right)^{-},\left(u_{a_{j}}^{-}, v_{a_{j}}^{-}\right)\right\} .
\end{aligned}
$$

For all the benefit criteria:

$$
\begin{aligned}
& \left\{\left(\Delta^{-1}\left(s_{\varphi_{j}}, \rho_{j}\right)\right)^{+},\left(u_{a_{j}}^{+}, v_{a_{j}}^{+}\right)\right\}=\left\{\max \left(\Delta^{-1}\left(s_{\varphi_{j}}, \rho_{j}\right)\right),\left(\max \left(u_{a_{j}}\right), \min \left(v_{a_{j}}\right)\right)\right\}, \\
& \left\{\left(\Delta^{-1}\left(s_{\varphi_{j}}, \rho_{j}\right)\right)^{-},\left(u_{a_{j}}^{-}, v_{a_{j}}^{-}\right)\right\}=\left\{\min \left(\Delta^{-1}\left(s_{\varphi_{j}}, \rho_{j}\right)\right),\left(\min \left(u_{a_{j}}\right), \max \left(v_{a_{j}}\right)\right)\right\} .
\end{aligned}
$$

For all the cost criteria:

$$
\begin{aligned}
& \left\{\left(\Delta^{-1}\left(s_{\varphi_{j}}, \rho_{j}\right)\right)^{+},\left(u_{a_{j}}^{+}, v_{a_{j}}^{+}\right)\right\}=\left\{\min \left(\Delta^{-1}\left(s_{\varphi_{j}}, \rho_{j}\right)\right),\left(\min \left(u_{a_{j}}\right), \max \left(v_{a_{j}}\right)\right)\right\}, \\
& \left\{\left(\Delta^{-1}\left(s_{\varphi_{j}}, \rho_{j}\right)\right)^{-},\left(u_{a_{j}}^{-}, v_{a_{j}}^{-}\right)\right\}=\left\{\max \left(\Delta^{-1}\left(s_{\varphi_{j}}, \rho_{j}\right)\right),\left(\max \left(u_{a_{j}}\right), \min \left(v_{a_{j}}\right)\right)\right\} .
\end{aligned}
$$

Step 4. Calculate $S_{i}$ and $P_{i}$ values using the following equations:

$$
\begin{gathered}
S_{i}=\sum_{j=1}^{n} \omega_{j} \frac{d\left(\left(\left(\Delta^{-1}\left(s_{\varphi_{j}}, \rho_{j}\right)\right)^{+},\left(u_{a_{j}}^{+}, v_{a_{j}}^{+}\right)\right),\left(\Delta^{-1}\left(s_{\varphi_{j}}, \rho_{j}\right),\left(u_{a_{j}}, v_{a_{j}}\right)\right)\right)}{\left.d\left(\left(\Delta^{-1}\left(s_{\varphi_{j}}, \rho_{j}\right)\right)^{+},\left(u_{a_{j}}^{+}, v_{a_{j}}^{+}\right)\right),\left(\Delta^{-1}\left(s_{\varphi_{j}}, \rho_{j}\right)\right)^{-},\left(u_{a_{j}}^{-}, v_{a_{j}}^{-}\right)\right)^{\prime}}, \\
P_{i}=\max \left\{\omega_{j} \frac{d\left(\left(\left(\Delta^{-1}\left(s_{\varphi_{j}}, \rho_{j}\right)\right)^{+},\left(u_{a_{j}}^{+}, v_{a_{j}}^{+}\right)\right),\left(\Delta^{-1}\left(s_{\varphi_{j}}, \rho_{j}\right),\left(u_{a_{j}}, v_{a_{j}}\right)\right)\right)}{d\left(\left(\left(\Delta^{-1}\left(s_{\varphi_{j}}, \rho_{j}\right)\right)^{+},\left(u_{a_{j}}^{+}, v_{a_{j}}^{+}\right)\right),\left(\Delta^{-1}\left(s_{\varphi_{j}}, \rho_{j}\right)\right)^{-},\left(u_{a_{j}}^{-}, v_{a_{j}}^{-}\right)\right)}\right\} .
\end{gathered}
$$


Here, $d$ denotes the normalized Hamming distance and $\omega_{j}$ means the weight of attributes with these conditions, $0 \leq \omega_{j} \leq 1, \sum_{j=1}^{n} \omega_{j}=1$.

Step 5: Compute $Q_{i}$ values as follows:

$$
Q_{i}=v \frac{S_{i}-S_{i}^{*}}{S_{i}^{-}-S_{i}^{*}}+(1-v) \frac{P_{i}-P_{i}^{*}}{P_{i}^{-}-P_{i}^{*}}
$$

where

$$
\begin{aligned}
& S_{i}^{*}=\min _{i} S_{i}, S_{i}^{-}=\max _{i} S_{i}, \\
& P_{i}^{*}=\min _{i} P_{i}, P_{i}^{-}=\max _{i} P_{i},
\end{aligned}
$$

where $v$ can be described as the decision-making mechanism coefficient. If $v>0.5$, it denotes "the maximum group utility"; if $v<0.5$, it denotes "the minimum regret", and if $v=0.5$, it denotes "equality".

Step 6: According to the $Q_{i}$ values, the optimal decision among the rank alternatives is the alternative with the minimum $Q$ value.

\section{Numerical Example and Comparative Analysis}

\subsection{Numerical Example}

In this section, we shall provide a numerical example to evaluate the human factors in the process of construction project management by using the P2TL-VIKOR model. Assume that five possible construction projects $\Phi_{i}(i=1,2,3,4,5)$ are to be selected and there are four evaluation criteria $\tau_{j}(j=1,2,3,4)$ to evaluate these construction projects: (1) $\tau_{1}$ is the workers' proficiency; (2) $\tau_{2}$ is the workers' safety awareness; (3) $\tau_{3}$ is the technical workers' quality; and (4) $\tau_{4}$ is the workers' emergency capacity. The five possible construction projects $\Phi_{i}(i=1,2,3,4,5)$ are to be evaluated through using P2TLNs with the four criteria by three experts, $\mathrm{E}^{k}$ (expert's weight $w=(0.29,0.38,0.33$ ), which have an attributes weight of $\left.\omega=(0.24,0.17,0.31,0.28)^{T}\right)$.

In order to carry out this evaluation, decision makers use language variables to express their evaluation, and the language variables of evaluation alternatives are shown in Table 1 . The following steps are used to evaluate the human factors associated with the five construction projects using the proposed P2TL-VIKOR method:

Table 1. Linguistic variables and their fuzzy numbers.

\begin{tabular}{cc}
\hline Linguistic Variable & Pythagorean 2-Tuple Linguistic Numbers \\
\hline Very low $(\mathrm{VL})$ & $\left(\left(\mathrm{s}_{0}, 0\right),(0.1,0.8)\right)$ \\
Low $(\mathrm{L})$ & $\left(\left(\mathrm{s}_{1}, 0\right),(0.2,0.7)\right)$ \\
Medium low $(\mathrm{ML})$ & $\left(\left(\mathrm{s}_{2}, 0\right),(0.3,0.6)\right)$ \\
Medium $(\mathrm{M})$ & $\left(\left(\mathrm{s}_{3}, 0\right),(0.5,0.5)\right)$ \\
Medium high $(\mathrm{MH})$ & $\left(\left(\mathrm{s}_{4}, 0\right),(0.6,0.3)\right)$ \\
High $(\mathrm{H})$ & $\left(\left(\mathrm{s}_{5}, 0\right),(0.7,0.2)\right.$ \\
Very high $(\mathrm{VH})$ & $\left(\left(\mathrm{s}_{6}, 0\right),(0.8,0.1)\right)$ \\
\hline
\end{tabular}

Step 1. Construct the evaluation matrix $R^{(3)}=\left(r_{i j}^{3}\right)_{5 \times 4}(i=1,2, \ldots, 5, j=1,2, \ldots, 4)$ of each decision maker as in Tables 2-4. Based on Tables 1-4 and Equation (9), the group Pythagorean 2-tuple linguistic fuzzy decision matrix is computed. Table 5 shows the results. 
Table 2. Rating alternatives on each criterion by $E_{1}$.

\begin{tabular}{ccccc}
\hline & $\tau_{1}$ & $\tau_{2}$ & $\tau_{3}$ & $\tau_{4}$ \\
\hline$\Phi_{1}$ & $\mathrm{M}$ & $\mathrm{H}$ & $\mathrm{ML}$ & $\mathrm{L}$ \\
$\Phi_{2}$ & $\mathrm{VL}$ & $\mathrm{L}$ & $\mathrm{L}$ & $\mathrm{VH}$ \\
$\Phi_{3}$ & $\mathrm{~L}$ & $\mathrm{VL}$ & $\mathrm{H}$ & $\mathrm{M}$ \\
$\Phi_{4}$ & $\mathrm{H}$ & $\mathrm{MH}$ & $\mathrm{ML}$ & $\mathrm{VH}$ \\
$\Phi_{5}$ & $\mathrm{VH}$ & $\mathrm{M}$ & $\mathrm{MH}$ & $\mathrm{VL}$ \\
\hline
\end{tabular}

Table 3. Rating alternatives on each criterion by $E_{2}$.

\begin{tabular}{ccccc}
\hline & $\tau_{1}$ & $\tau_{2}$ & $\tau_{3}$ & $\tau_{4}$ \\
\hline$\Phi_{1}$ & $\mathrm{M}$ & $\mathrm{MH}$ & $\mathrm{H}$ & $\mathrm{ML}$ \\
$\Phi_{2}$ & $\mathrm{~L}$ & $\mathrm{VL}$ & $\mathrm{L}$ & $\mathrm{H}$ \\
$\Phi_{3}$ & $\mathrm{H}$ & $\mathrm{M}$ & $\mathrm{M}$ & $\mathrm{VL}$ \\
$\Phi_{4}$ & $\mathrm{VH}$ & $\mathrm{ML}$ & $\mathrm{M}$ & $\mathrm{MH}$ \\
$\Phi_{5}$ & $\mathrm{ML}$ & $\mathrm{H}$ & $\mathrm{H}$ & $\mathrm{M}$ \\
\hline
\end{tabular}

Table 4. Rating alternatives on each criterion by $E_{3}$.

\begin{tabular}{ccccc}
\hline & $\tau_{1}$ & $\tau_{2}$ & $\tau_{3}$ & $\tau_{4}$ \\
\hline$\Phi_{1}$ & $\mathrm{MH}$ & $\mathrm{VL}$ & $\mathrm{L}$ & $\mathrm{MH}$ \\
$\Phi_{2}$ & $\mathrm{M}$ & $\mathrm{VH}$ & $\mathrm{ML}$ & $\mathrm{L}$ \\
$\Phi_{3}$ & $\mathrm{ML}$ & $\mathrm{H}$ & $\mathrm{H}$ & $\mathrm{L}$ \\
$\Phi_{4}$ & $\mathrm{~L}$ & $\mathrm{M}$ & $\mathrm{H}$ & $\mathrm{VH}$ \\
$\Phi_{5}$ & $\mathrm{VL}$ & $\mathrm{M}$ & $\mathrm{MH}$ & $\mathrm{VL}$ \\
\hline
\end{tabular}

Table 5. The group Pythagorean 2-tuple linguistic decision matrix $R$.

\begin{tabular}{ccc}
\hline & $\tau_{1}$ & $\tau_{2}$ \\
\hline$\Phi_{1}$ & $<\left(\mathrm{s}_{3}, 0.33\right),(0.5369,0.5165)>$ & $<\left(\mathrm{s}_{3},-0.03\right),(0.555,0.5879)>$ \\
$\Phi_{2}$ & $<\left(\mathrm{s}_{1}, 0.37\right),(0.3274,0.6947)>$ & $<\left(\mathrm{s}_{2}, 0.27\right),(0.5452,0.4297)>$ \\
$\Phi_{3}$ & $<\left(\mathrm{s}_{3},-0.15\right),(0.5082,0.4583)>$ & $<\left(\mathrm{s}_{3},-0.21\right),(0.5332,0.4518)>$ \\
$\Phi_{4}$ & $<\left(\mathrm{s}_{4}, 0.06\right),(0.6705,0.3706)>$ & $<\left(\mathrm{s}_{3},-0.09\right),(0.4786,0.6552)>$ \\
$\Phi_{5}$ & $<\left(\mathrm{s}_{3},-0.5\right),(0.5338,0.7651)>$ & $<\left(\mathrm{s}_{4},-0.24\right),(0.5935,0.4316)>$ \\
\hline & $\tau_{3}$ & $\tau_{4}$ \\
\hline$\Phi_{1}$ & $<(\mathrm{s} 3,-0.19),(0.5067,0.4823)>$ & $<(\mathrm{s} 2,0.37),(0.4209,0.5535)>$ \\
$\Phi_{2}$ & $<(\mathrm{s} 1,0.33),(0.2383,0.7378)>$ & $<(\mathrm{s} 4,-0.03),(0.6573,0.4823)>$ \\
$\Phi_{3}$ & $<(\mathrm{s} 4,0.24),(0.6399,0.4518)>$ & $<(\mathrm{s} 1,0.2),(0.3095,0.8167)>$ \\
$\Phi_{4}$ & $<(\mathrm{s} 3,0.37),(0.5491,0.4518)>$ & $<(\mathrm{s} 5,0.24),(0.743,0.296)>$ \\
$\Phi_{5}$ & $<(\mathrm{s} 4,0.38),(0.6426,0.3646)>$ & $<(\mathrm{s} 1,0.14),(0.3303,0.7139)>$ \\
\hline
\end{tabular}

Step 2. Determine the $R_{j}^{+}$and $R_{j}^{-}$by Equations (13) and (14).

$$
\begin{gathered}
R_{j}^{+}=\left\{\begin{array}{c}
\left\langle\left(\mathrm{s}_{4}, 0.06\right),(0.6705,0.3706)\right\rangle \\
\left\langle\left(\mathrm{s}_{4},-0.24\right),(0.5935,0.4297)\right\rangle \\
\left\langle\left(\mathrm{s}_{4}, 0.38\right),(0.6426,0.3646)\right\rangle \\
\left\langle\left(\mathrm{s}_{5}, 0.24\right),(0.743,0.296)\right\rangle
\end{array}\right\}, \\
R_{j}^{-}=\left\{\begin{array}{c}
\left\langle\left(\mathrm{s}_{1}, 0.37\right),(0.3274,0.7651)\right\rangle \\
\left\langle\left(\mathrm{s}_{2}, 0.27\right),(0.4786,0.6552)\right\rangle \\
\left\langle\left(\mathrm{s}_{1}, 0.33\right),(0.2383,0.7378)\right\rangle \\
\left\langle\left(\mathrm{s}_{1}, 0.14\right),(0.3095,0.8167)\right\rangle
\end{array}\right\} .
\end{gathered}
$$

Step 3. Compute $S_{i}$ and $P_{i}$ values by Equations (17) and (18). 


$$
\begin{aligned}
& S_{1}=0.5917, S_{2}=0.7793, S_{3}=0.5228, S_{4}=0.2563, S_{5}=0.4590, \\
& P_{1}=0.2186, P_{2}=0.3100, P_{3}=0.2790, P_{4}=0.1362, P_{5}=0.2724 .
\end{aligned}
$$

Step 4. Calculate $Q_{i}$ values as follows (Let $v=0.4$ ):

$$
Q_{1}=0.5411, Q_{2}=1.0000, Q_{3}=0.6968, Q_{4}=0.0000, Q_{5}=0.6253
$$

Step 5. According to the $Q_{i}$ values, the optimal decision among the rank alternatives is the alternative with the minimum $Q$ value: $\Phi_{4}>\Phi_{1}>\Phi_{5}>\Phi_{3}>\Phi_{2}$. Thus, the most optimal alternative is $\Phi_{4}$.

\subsection{Comparative Analyses}

In this part, we will make some comparative analyses to compare in our proposed P2TL-VIKOR model the P2TLWA and P2TLWG operators defined by Wei, Lu, Alsaadi, Hayat and Alsaedi [50], and the P2TL-TODIM method proposed by Huang and Wei [22].

The comparison results of different methods are as follows.

It is clear from Table 6 that the results are slightly different in ranking of alternatives, but the best alternative is always $\Phi_{4}$ by comparing the values of our proposed P2TL-VIKOR method with the P2TLWA/P2TLWG operators and the P2TL-TODIM model. Notably, in practical MADM problems, the P2TL-VIKOR method fully considers the conflict between attributes, which is more reasonable and scientific. All these methods have their good advantages: (1) P2TLWA operators emphasize the group influences; (2) the P2TLWG operator emphasizes individual influences; (3) the P2TL-TODIM method based on the prospect theory is exactly a kind of method that considers the influence of the experts' psychological behaviors factors on the decision results; and (4) the P2TL-VIKOR method takes into account the contradictory criteria such as the objectivity of decision makers and the complexity of the decision environment, so as to obtain more useful and scientific evaluation information.

Table 6. Rank of alternatives by using different methods.

\begin{tabular}{cc}
\hline Methods & Order \\
\hline P2TLWA & $\Phi_{4}>\Phi_{5}>\Phi_{3}>\Phi_{1}>\Phi_{2}$ \\
P2TLWG & $\Phi_{4}>\Phi_{1}>\Phi_{5}>\Phi_{3}>\Phi_{2}$ \\
P2TL-TODIM & $\Phi_{4}>\Phi_{5}>\Phi_{3}>\Phi_{1}>\Phi_{2}$ \\
P2TL-VIKOR & $\Phi_{4}>\Phi_{1}>\Phi_{5}>\Phi_{3}>\Phi_{2}$ \\
\hline
\end{tabular}

\section{Conclusions}

Human factors are not only the leading factors affecting the quality of construction projects, but also the most basic and core factors in the quality assurance system; so, the evaluation of human factors in construction projects is particularly critical. Human factor evaluation in construction projects is a MADM problem, and the information available for decision making is vague or uncertain in nature. Therefore, we used language variables to express the preferences of experts. The Pythagorean 2-tuple linguistic sets (P2TLSs) can well reflect uncertain or fuzzy information and solve these kinds of problems, and the original VIKOR is characterized by handling conflicting attributes. Naturally, we combined the Pythagorean 2-tuple linguistic sets with VIKOR, and the recommended method was systematically applied to the human factor evaluation of five construction projects to find an optimal construction project. The comparative study shows that the proposed MADM algorithm is feasible. This method is very effective and useful for decision making.

The main contributions of this study is fourfold: (1) the Pythagorean 2-tuple linguistic VIKOR (P2TL-VIKOR) method is designed to tackle the Pythagorean 2-tuple linguistic MAGDM issues; (2) a 
case study for evaluating human factors in construction project management is designed to show the developed approach; (3) some comparative studies are provided with the existing methods to give effect to the rationality of P2TL-VIKOR; and (4) the proposed method can also successfully contribute to the selection of suitable alternatives in other selection issues.

In the future, the proposed method can be expanded to deal with other decision-making issues, such as the selection of green suppliers, the location of waste disposal station, and so on.

Author Contributions: T.H., G.W. (Guiwu Wei), J.L., C.W. (Cun Wei) and R.L. conceived and worked together to achieve this work, T.H. compiled the computing program by Excel and analyzed the data, T.H. and G.W. (Guiwu Wei) wrote the paper. Finally, all the authors have read and approved the final manuscript.

Funding: The work was supported by the National Natural Science Foundation of China under Grant No. 71571128 and the Humanities and Social Sciences Foundation of Ministry of Education of the People's Republic of China (14YJCZH091). The APC was funded by Humanities and Social Sciences Foundation of Ministry of Education of the People's Republic of China (14YJCZH091).

Conflicts of Interest: The authors declare no conflicts of interest.

\section{References}

1. Ning, X.; Wang, L.G. Construction Site Layout Evaluation by Intuitionistic Fuzzy TOPSIS Model. In Frontiers of Green Building, Materials and Civil Engineering; Sun, D., Sung, W.P., Chen, R., Eds.; Scientific.net: Baech, Switzerland, 2011; Volumes 71-78, pp. 583-588.

2. $\mathrm{Lu}, \mathrm{Y}$. Research of models and methods of construction project information management with 2-tuple linguistic information. Inf. Int. Interdiscip. J. 2012, 15, 3911-3916.

3. Gu, X.; Zhao, P.; Wang, Y. Models for multiple attribute decision making based on the Einstein correlated aggregation operators with interval-valued intuitionistic fuzzy information. J. Intell. Fuzzy Syst. 2014, 26, 2047-2055.

4. Wu, S.J.; Wang, J.; Wei, G.W.; Wei, Y. Research on construction engineering project risk assessment with some 2-tuple linguistic neutrosophic hamy mean operators. Sustainability 2018, 10, 1536. [CrossRef]

5. Zadeh, L.A. Fuzzy sets. Inf. Control 1965, 8, 338-356. [CrossRef]

6. Atanassov, K.T. Intuitionistic fuzzy sets. Fuzzy Sets Syst. 1986, 20, 87-96. [CrossRef]

7. Li, Z.X.; Gao, H.; Wei, G.W. Methods for multiple attribute group decision making based on intuitionistic fuzzy dombi hamy mean operators. Symmetry 2018, 10, 574. [CrossRef]

8. Wei, G.W.; Wang, J.; Lu, M.; Wu, J.; Wei, C. Similarity Measures of Spherical Fuzzy Sets Based on Cosine Function and Their Applications. IEEE Access 2019, 7, 159069-159080. [CrossRef]

9. Wei, G.W. 2-Tuple intuitionistic fuzzy linguistic aggregation operators in multiple attribute decision making. Iran. J. Fuzzy Syst. 2019, 16, 159-174.

10. Wu, L.P.; Wang, J.; Gao, H. Models for competiveness evaluation of tourist destination with some interval-valued intuitionistic fuzzy Hamy mean operators. J. Intell. Fuzzy Syst. 2019, 36, 5693-5709. [CrossRef]

11. Gao, H.; Wu, J.; Wei, C.; Wei, G.W. MADM method with Interval-valued Bipolar Uncertain Linguistic Information for Evaluating the Computer Network Security. IEEE Access 2019, 7, 151506-151524. [CrossRef]

12. Yager, R.R. Pythagorean Fuzzy Subsets. In Proceedings of the Joint IFSA World Congress and NAFIPS Annual Meeting (IFSA/NAFIPS), Edmonton, AB, Canada, 24-28 June 2013; pp. 57-61.

13. Lu, J.P.; Tang, X.Y.; Wei, G.W.; Wei, C.; Wei, Y. Bidirectional project method for dual hesitant Pythagorean fuzzy multiple attribute decision-making and their application to performance assessment of new rural construction. Int. J. Intell. Syst. 2019, 34, 1920-1934. [CrossRef]

14. Tang, M.; Wang, J.; Lu, J.P.; Wei, G.W.; Wei, C.; Wei, Y. Dual hesitant pythagorean fuzzy heronian mean operators in multiple attribute decision making. Mathematics 2019, 7, 344. [CrossRef]

15. Wang, J.; Gao, H.; Wei, G.W. The generalized dice similarity measures for Pythagorean fuzzy multiple attribute group decision making. Int. J. Intell. Syst. 2019, 34, 1158-1183. [CrossRef]

16. Wei, G.W.; Wang, J.; Wei, C.; Wei, Y.; Zhang, Y. Dual hesitant pythagorean fuzzy hamy mean operators in multiple attribute decision making. IEEE Access 2019, 7, 86697-86716. [CrossRef]

17. Zhang, X.L.; Xu, Z.S. Extension of TOPSIS to multiple criteria decision making with Pythagorean fuzzy sets. Int. J. Intell. Syst. 2014, 29, 1061-1078. [CrossRef] 
18. Zhang, X.L. Multicriteria Pythagorean fuzzy decision analysis: A hierarchical QUALIFLEX approach with the closeness index-based ranking methods. Inf. Sci. 2016, 330, 104-124. [CrossRef]

19. Ren, P.J.; Xu, Z.S.; Gou, X.J. Pythagorean fuzzy TODIM approach to multi-criteria decision making. Appl. Soft Comput. 2016, 42, 246-259. [CrossRef]

20. Bolturk, E. Pythagorean fuzzy CODAS and its application to supplier selection in a manufacturing firm. J. Enterp. Inf. Manag. 2018, 31, 550-564. [CrossRef]

21. Chen, T.Y. Remoteness index-based Pythagorean fuzzy VIKOR methods with a generalized distance measure for multiple criteria decision analysis. Inf. Fusion 2018, 41, 129-150. [CrossRef]

22. Huang, Y.H.; Wei, G.W. TODIM method for Pythagorean 2-tuple linguistic multiple attribute decision making. J. Intell. Fuzzy Syst. 2018, 35, 901-915. [CrossRef]

23. Ilbahar, E.; Karasan, A.; Cebi, S.; Kahraman, C. A novel approach to risk assessment for occupational health and safety using Pythagorean fuzzy AHP \& fuzzy inference system. Saf. Sci. 2018, 103, 124-136.

24. Khan, M.S.A.; Abdullah, S.; Ali, M.Y.; Hussain, I.; Farooq, M. Extension of TOPSIS method base on Choquet integral under interval-valued Pythagorean fuzzy environment. J. Intell. Fuzzy Syst. 2018, 34, 267-282. [CrossRef]

25. Perez-Dominguez, L.; Rodriguez-Picon, L.A.; Alvarado-Iniesta, A.; Cruz, D.L.; Xu, Z.S. MOORA under Pythagorean fuzzy set for multiple criteria decision making. Complexity 2018, 2018, 2602376. [CrossRef]

26. Xue, W.T.; Xu, Z.S.; Zhang, X.L.; Tian, X.L. Pythagorean fuzzy LINMAP method based on the entropy theory for railway project investment decision making. Int. J. Intell. Syst. 2018, 33, 93-125. [CrossRef]

27. Opricovic, S.; Tzeng, G.H. Compromise solution by MCDM methods: A comparative analysis of VIKOR and TOPSIS. Eur. J. Oper. Res. 2007, 156, 445-455. [CrossRef]

28. Benayoun, R.; Roy, B.; Sussman, B. ELECTRE: Une méthode pour guider le choix en présence de points de vue multiples. Rev. Franaise Inf. Rech. Opérationnelle 1966, 3, 31-56.

29. Mareschal, B.; Brans, J.P.; Vincke, P. Prométhée, a new family of outranking methods in multicriteria analysis. ULB Inst. Repos. 1984.

30. Wei, G.W.; Wang, H.J.; Lin, R.; Zhao, X.F. Grey relational analysis method for intuitionistic fuzzy multiple attribute decision making with preference information on alternatives. Int. J. Comput. Intell. Syst. 2011, 4, 164-173. [CrossRef]

31. Hwang, C.L.; Yoon, K. Multiple Attribute Decision Making. In Methods and Applications A State-of-the-Art Survey; Springer: Berlin, Germany, 1981.

32. Wang, J.; Wei, G.W.; Lu, M. TODIM method for multiple attribute group decision making under 2-tuple linguistic neutrosophic environment. Symmetry 2018, 10, 486. [CrossRef]

33. Wei, G.W. TODIM method for picture fuzzy multiple attribute decision making. Informatica 2018, 29, 555-566. [CrossRef]

34. Gomes, L.; Lima, M. TODIM: Basics and application to multicriteria ranking of projects with environmental impacts. Found. Comput. Decis. Sci. 1979, 16, 113-127.

35. Devi, K. Extension of VIKOR method in intuitionistic fuzzy environment for robot selection. Expert Syst. Appl. 2011, 38, 14163-14168. [CrossRef]

36. Du, Y.; Liu, P.D. Extended fuzzy VIKOR method with intuitionistic trapezoidal fuzzy numbers. Inf. Int. Interdiscip. J. 2011, 14, 2575-2583.

37. Park, J.H.; Cho, H.J.; Kwun, Y.C. Extension of the VIKOR method for group decision making with interval-valued intuitionistic fuzzy information. Fuzzy Optim. Decis. Mak. 2011, 10, 233-253. [CrossRef]

38. Chatterjee, K.; Kar, M.B.; Kar, S. Strategic Decisions Using Intuitionistic Fuzzy Vikor Method for Information System (IS) Outsourcing. In Proceedings of the 2013 International Symposium on Computational and Business Intelligence, New Delhi, India, 24-26 August 2013; pp. 123-126.

39. Liao, H.C.; Xu, Z.S. A VIKOR-based method for hesitant fuzzy multi-criteria decision making. Fuzzy Optim. Decis. Mak. 2013, 12, 373-392. [CrossRef]

40. Liu, H.C.; Liu, L.; Wu, J. Material selection using an interval 2-tuple linguistic VIKOR method considering subjective and objective weights. Mater. Des. 2013, 52, 158-167. [CrossRef]

41. Wei, G.; Zhang, N.A. A multiple criteria hesitant fuzzy decision making with shapley value-based VIKOR method. J. Intell. Fuzzy Syst. 2014, 26, 1065-1075. 
42. Bausys, R.; Zavadskas, E.K. Multicriteria decision making approach by VIKOR under interval neutrosophic set environment. Econ. Comput. Econ. Cybern. Stud. Res. 2015, 49, 33-48.

43. Dammak, F.; Baccour, L.; Alimi, A.M. A comparative analysis for multi-attribute decision making methods: TOPSIS, AHP, VIKOR using intuitionistic fuzzy sets. In Proceedings of the 2015 IEEE International Conference on Fuzzy Systems, Istanbul, Turkey, 2-5 August 2015.

44. Liao, H.C.; Xu, Z.S. Approaches to manage hesitant fuzzy linguistic information based on the cosine distance and similarity measures for HFLTSs and their application in qualitative decision making. Expert Syst. Appl. 2015, 42, 5328-5336. [CrossRef]

45. You, X.Y.; You, J.X.; Liu, H.C.; Zhen, L. Group multi-criteria supplier selection using an extended VIKOR method with interval 2-tuple linguistic information. Expert Syst. Appl. 2015, 42, 1906-1916. [CrossRef]

46. Buyukozkan, G.; Feyzioglu, O.; Gocer, F. Evaluation of Hospital Web Services Using Intuitionistic Fuzzy AHP and Intuitionistic Fuzzy VIKOR. In Proceedings of the 2016 IEEE International Conference on Industrial Engineering and Engineering Management (IEEM), Bali, Indonesia, 4-7 December 2016; pp. 607-611.

47. Zhang, F.Y.; Luo, L.; Liao, H.C.; Zhu, T.; Shi, Y.K.; Shen, W.W. Inpatient admission assessment in West China Hospital based on hesitant fuzzy linguistic VIKOR method. J. Intell. Fuzzy Syst. 2016, 30, 3143-3154. [CrossRef]

48. Hu, J.H.; Pan, L.; Chen, X.H. An interval neutrosophic projection-based VIKOR method for selecting doctors. Cogn. Comput. 2017, 9, 801-816. [CrossRef]

49. Wang, L.; Zhang, H.Y.; Wang, J.Q.; Li, L. Picture fuzzy normalized projection-based VIKOR method for the risk evaluation of construction project. Appl. Soft Comput. 2018, 64, 216-226. [CrossRef]

50. Wei, G.; Lu, M.; Alsaadi, F.E.; Hayat, T.; Alsaedi, A. Pythagorean 2-tuple linguistic aggregation operators in multiple attribute decision making. J. Intell. Fuzzy Syst. 2017. [CrossRef]

51. Wei, G.W. Pythagorean fuzzy interaction aggregation operators and their application to multiple attribute decision making. J. Intell. Fuzzy Syst. 2017, 33, 2119-2132. [CrossRef]

52. Herrera, F.; Martinez, L. A 2-tuple fuzzy linguistic representation model for computing with words. IEEE Trans. Fuzzy Syst. 2000, 8, 746-752.

(C) 2019 by the authors. Licensee MDPI, Basel, Switzerland. This article is an open access article distributed under the terms and conditions of the Creative Commons Attribution (CC BY) license (http://creativecommons.org/licenses/by/4.0/). 